\title{
"The Management of Scabies Infection among the Outdoor Patients of BIRDEM General Hospital, Dhaka, Bangladesh"
}

\author{
M. Moniruzzaman Khan ${ }^{1}$, Mir Nazrul Islam², Hosney Ara Begum ${ }^{3}$, Md. Kamrul Ahsan ${ }^{4}$
}

${ }^{1}$ Assistant Professor, Department of Skin, BIRDEM General Hospital, Dhaka, Bangladesh

${ }^{2}$ Professor, Department of Skin, BIRDEM General Hospital, Dhaka, Bangladesh

${ }^{3}$ Associate Professor, Department of Skin, BIRDEM General Hospital, Dhaka, Bangladesh

${ }^{4}$ Associate Professor, Department of Skin, BIRDEM General Hospital, Dhaka, Bangladesh

DOI: $10.36348 /$ sjmps.2020.v06i05.003

| Received: 18.01.2020 | Accepted: 02.02.2020 | Published: 19.05.2020

*Corresponding author: M. Moniruzzaman Khan

\section{Abstract}

Introduction: Scabies is a common contagious parasitic dermatosis. Transmission of the mite Sarcoptes scabiei var hominis generally occurs by skin-to-skin contact, but with crusted scabies it may also occur through fomites, such as infected clothing or bedding. Diagnosis is usually clinical. Objective: To find out The Management of Scabies Infection among the Outdoor Patients of BIRDEM General Hospital, Dhaka, Bangladesh. Materials and Methods: Scope and Delimitation of the Study. This study focused the management of scabies. This study was conducted among the OPD patients in BIRDEM hospital. The study was conducted from January to December 2017.The diagnoses of scabies of the potential respondents were based on the set criteria. Only those diagnose clinically with scabies were included in this study. There were no scraping procedures (acarus test) done to confirm the diagnosis of scabies. Other skin diseases aside from scabies were not included in the study. Results: A 2017 updated Cochrane review concluded that management of scabies is based on topical scabicides, mainly 5\% permethrin. However, oral ivermectin, although not licensed in many countries, may be useful, particularly for patients who cannot tolerate or comply with topical therapy and in institutional scabies epidemics. Patients should also receive detailed information about the infestation to limit further spreading. Cases resulting from close physical or sexual contact, even without symptoms, should be systematically treated. Hygienic measures should be taken after treatment is completed. Patients should be followed to confirm cure, including resolution of itching, which may take up to 4 weeks or longer. Conclusion: At the end of this study, the researcher was able to arrive at the following Conclusion Scabies is more common where overcrowded conditions prevail; it can affect any individual irrespective of social status, personal hygiene, profession, gender, age or ethic origin. These include increased number of household members, presence of other family members with scabies, overcrowding, poverty and low educational attainment. Children (1-12 yrs.) have the highest incidence of scabies as compared to the other age group.

Keywords: Benzyl benzoatej ivermectin, Permethrin, Scabicides, Scabies.

Copyright @ 2020: This is an open-access article distributed under the terms of the Creative Commons Attribution license which permits unrestricted use, distribution, and reproduction in any medium for non-commercial use (NonCommercial, or CC-BY-NC) provided the original author and source are credited.

\section{INTRODUCTION}

Scabies infection is an important skin disease. It is public health problem. There are many public health problems from which people of the under developed countries suffer much because of ignorance, illiteracy, poverty and apathy towards health problem. All these factors exeunt in Bangladesh where scabies infection is a problem. It has associated with densely population, poverty, wanting of health education and social upheaval when hygiene becomes relatively unimportant. Scabies infection increase when people are herded together and facilities for washing the body and clothes are reduced. Anyone gets scabies but at higher risk includes; sexually active adults, prison inmates, people in institutional care, people live in crowded condition, people in child care facilities. Our geographical and socio-economic condition is suitable for scabies infection. There are a number of variables that can make people more susceptible to a scabies infection. The peoples who have recently taken a course of antibiotics or taken oral steroids are more likely to contact an infection. The patients who are suffering from diabetes, cancer or HIV which has weakened their immune system are commonly affected by scabies infection. Scabies is an intensely itchy parasitic infection of the skin that is caused by the Sarcoptes scabiei mite. It occurs throughout the world, but is particularly problematic in areas of poor sanitation, overcrowding, and social disruption. The global 
prevalence of scabies is estimated at 300 million cases [1], with large variations between countries. In the UK, no up-to-date robust prevalence data exist, but general practitioners recorded approximately 1200 new cases per year in the 1990s [2]. In resource-rich communities, scabies tends to occur in cyclical epidemics, particularly within institutional-living situations such as nursing homes [3], or the army [4]. There is some seasonal variation with incidence being greater in the winter than the summer, perhaps related to the tendency for more indoor overcrowding in colder weather [2]. In resource-poor communities, the occurrence pat-tern is quite different with the disease being endemic in many areas [5]. For example, the prevalence of scabies among the remote Aboriginal communities of Northern Australia is around $50 \%$ in children and $25 \%$ in adults [6]. The prevalence of infection in a community is potentially influenced by changes in social attitudes, population movements, wars, misdiagnosis, inadequate treatment, and changes in the immune status of the population. Scabies infestation represents a considerable burden of ill health in many communities, and although the disease is rarely life threatening, it causes widespread debilitation and misery ([7] 1989). The life cycle of S. scabiei begins with the pregnant female laying two to three eggs a day in burrows several millimetres to several centimetres in length in the stratum corneum (outermost layer) of the skin. After about 50 to 72 hours, larvae emerge and make new burrows. They mature, mate, and repeat this 10- to 17day cycle. Mites usually live for 30 to 60 days [7]. Humans are the main reservoir for S. scabiei var. hominis (variety of the mite named to reflect the main host species). Scabies is usually 2Interventions for treating scabies. Published by John Wiley \& Sons, Ltd. spread person to person via direct skin contact, including sexual contact, though transfer via inanimate objects such as clothing or furnishings is also possible [8]. The mite can burrow beneath the skin within 2.5 minutes, though around 20 minutes is more usual [1]. The level of infectiousness of an individual depends in part on the number of mites harboured, which can vary from just a single mite to millions [5]. Humans can also be transiently infected by the genetically distinct animal varieties of S. scabiei (eg var. canis), though cross infectivity is low $[9,10,11]$.

\section{OBJeCtIVe}

To find out the management of scabies infection among the outdoor Patients of BIRDEM General Hospital, Dhaka, Bangladesh.

\section{Materials and Methods}

Scope and Delimitation of the Study. This study focused the management of scabies. This study was conducted among the OPD patients in BIRDEM General Hospital, Dhaka, Bangladesh. The study was conducted from January to December 2017. The diagnoses of scabies of the potential respondents were based on the set criteria. Only those diagnose clinically with scabies were included in this study. There were no scraping procedures (acarus test) done to confirm the diagnosis of scabies. Other skin diseases aside from scabies were not included in the study.

Research Design: This study utilized quasiexperimental research design to determine the efficacy management of scabies among selected area.

Research Setting: This study was done on the Department of Dermatology (outpatient department), Bangladesh Institute of Research and Rehabilitation in diabetes, Endocrine and metabolic disorders (BIRDEM), Dhaka, Bangladesh.

\section{Respondents \\ Inclusion Criteria}

a) Respondents who diagnose clinically with scabies.

b) Children who is more than 2 months old

c) Respondents with no secondary bacterial infections (eg. cellulitis, impetigo)

d) Respondents who does not Infect with other Skin disease.

Sampling Design: A purposive sampling deign was used in this study. Those who qualify from the set criteria were enrolled to the study.

Data Gathering: Data was collected through face to face interview of the respondents by using a pre-tested interviews schedule, before data collection the patients were examined by the professional doctor and confirmed about the scabies infection, the purpose of the study was explained first to the patients to build the concept so that the patients answer the question to the base of their knowledge, each interview took about fifteen minutes. The interview schedule was rechecked. Other skin diseases were diagnosed by the researcher like psoriasis, contact dermatitis, folliculitis, chronic urticaria, insect bites and scabies with secondary bacterial infection (impetigo).

\section{Criteria for Clinical Diagnosis of Scabies* History}

Regardless of age or socioeconomic status, presents with severe persistent pruritus

History of skin-to-skin contact in the family members with pruritus

Multiple family members were involved

Nocturnal pruritus, which is a highly characteristic complaint associated with scabies infestation.

Work station and its environment. 


\section{Physical Exam**}

A short elevated serpiginous (S-shaped) track in the superficial epidermis, known as a burrow, which is pathognomonic of scabies infestation.

Burrows or runs appearing as a thin (approximately the width of a human hair), short (perhaps 2-3 $\mathrm{mm}$ in length), and gray brown, wavy channel on the skin.

A small vesicle or papule appearing at the end of the burrow or occur independently. Burrows best detected in the web spaces of the fingers, flexor aspects of the wrists, antecubital fossa, axilla, umbilicus, buttocks, and feet.

*Diagnostic criteria for scabies: @ least 2 symptoms (based on history) plus @ least 2 signs (based on Physical exam)

** Compared to adults, scabies in infants and young children tend to be more disseminated and, while the head and face usually are spared in adults, they may be affected in the very young. Furthermore, the respondents were advised to have hygienic practices and wash their clothes and bed linens with warm water during the course of treatment.

\section{Laboratory Procedure}

\section{Skin scraping:}

Diagnosis is by identification of the mite, eggs or faecal matter from skin scrapings. A clinical diagnosis may be made by a combination of severe itching especially at night and a typical or atypical distribution of a rash in persons who have had skin to skin contact with suspected or diagnosed cases. If clinical diagnosis is difficult, obtaining skin scrapings for the scabies mites or their faecal pellets may be helpful.
a) Equipment needed
b) Magnifying glass
c) Scalpel blade
d) Needle

e) Mineral oil (liquid paraffin) - (available from the Microbiology Department)

f) Glass slides (available from the Microbiology Department)

Procedure: The mite usually hides just in front of the papule at the closed end of the burrow and can sometimes be seen as a dark spot (on white skin, vice versa on dark). Since mites stick to steel, opening the head of the burrow with a needle can allow it to be removed. The best technique is to find an unexcoriated patch of papules, place a drop or two of mineral oil on the skin, which may reveal the burrow, and scrape the blade of a \#15 scalpel vigorously over the skin surface to remove the top of the papules and burrow. Remove the slurry in oil to a glass slide and take to the microbiology laboratory for examination under the low power of a microscope. Mites, eggs and faecal pellets may be seen. If the patient is male and you see nodules on the penis and scrotum, or if similar lesions are seen on the anterior fold of the axilla in either sex, these are almost pathognomonic even in the absence of any positive finding of mites. The collected data from the respondents were transferred to a suitable designed master sheet for processing and subsequent analysis. Then the statistics was calculated.

\section{ObServation and Results}

The General objective of the study was to determine the prevalence of Scabies infection in the study area, Bangladesh Institute of Research and Rehabilitation in Diabetes, Endocrine and Metabolic Disorders (BIRDEM), Dhaka, Bangladesh. In order to adopt a suitable control strategy. And the specific objective was to determine severity of scabies infection, clinical procedure and treatment strategy. In view of this, the study was designed in such a manner that data might be collected by personal interview. After collecting and Analyzing data, following results are obtained which are given in tables and discussed.

Table-1: Distribution of population by age groups $(\mathrm{N}=105)$

\begin{tabular}{|c|c|c|}
\hline $\begin{array}{c}\text { Age groups in } \\
\text { year }\end{array}$ & $\begin{array}{c}\text { Number of } \\
\text { patients }\end{array}$ & $\begin{array}{c}\text { Prevalence } \\
(\boldsymbol{\%})\end{array}$ \\
\hline $\mathbf{0 - 6}$ & 17 & 16.20 \\
\hline $\mathbf{7 - 1 2}$ & 22 & 20.95 \\
\hline $\mathbf{1 3 - 1 8}$ & 11 & 10.43 \\
\hline $\mathbf{1 9 - 2 4}$ & 15 & 14.28 \\
\hline $\mathbf{2 5 - 3 0}$ & 9 & 8.5 \\
\hline $\mathbf{3 1 - 3 6}$ & 5 & 4.7 \\
\hline $\mathbf{3 7 - 4 2}$ & 8 & 7.6 \\
\hline $\mathbf{4 3 - 4 8}$ & 4 & 3.8 \\
\hline $\mathbf{4 9 - 5 4}$ & 4 & 3.8 \\
\hline $\mathbf{5 5}+$ & 10 & 9.5 \\
\hline Total & 105 & 100 \\
\hline
\end{tabular}


It appears that maximum population affected with Scabies infection were aged between 0-6 years $(16.20 \%)$ and $7-12$ years $(20-95 \%)$ and minimum were between 43-48 years (prevalence 3.8\%) and 49-54 years (prevalence $3.8 \%$ ) [Table-1 \& Figure-1].

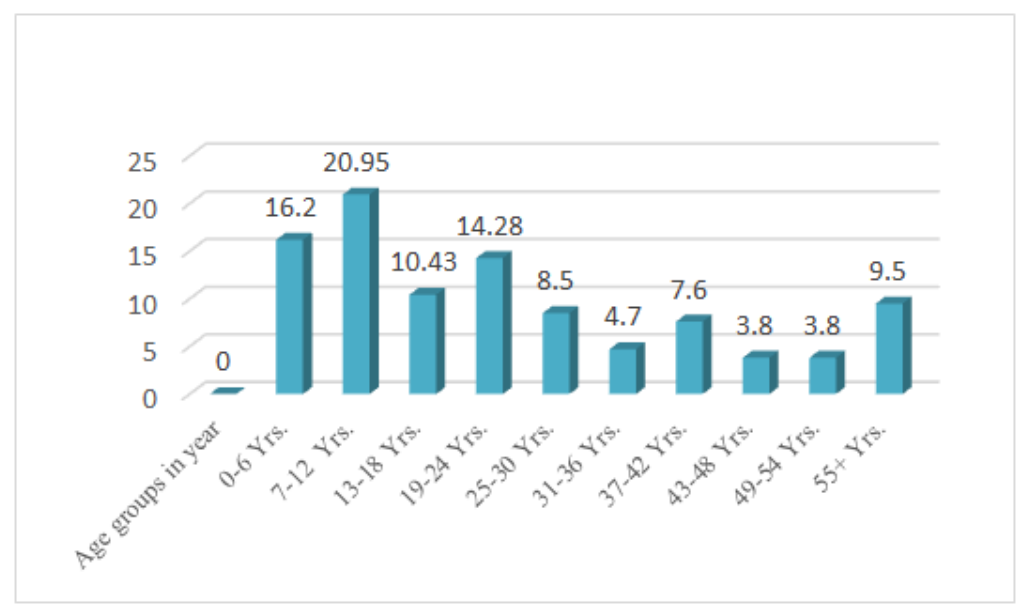

Fig-1: Distribution of population by age groups.

Table-2: Distribution of population by sex groups $(\mathrm{N}=105)$

\begin{tabular}{|c|c|c|}
\hline Sex group & Number of patients & Prevalence (\%) \\
\hline Female & 61 & 58.09 \\
\hline Male & 44 & 41.91 \\
\hline Total & 105 & 100 \\
\hline
\end{tabular}

The result shows that among the 105 scabies infected patients $61(58.09 \%)$ were female and $44(41.91 \%)$ were male. It shows that the sex ratio in scabies infection patients is female: male $=61: 44$. So it appears that females are more affected than male [Table-2].

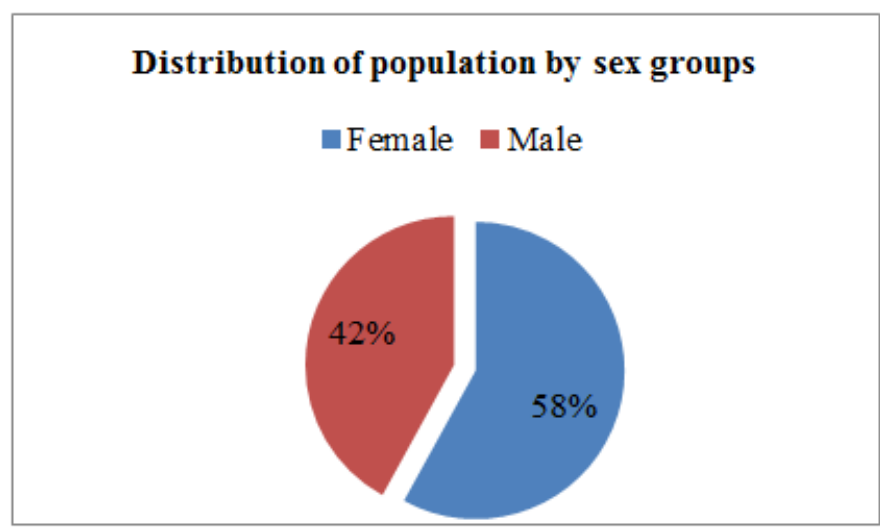

Fig-2: Distribution of population by sex groups

Table-3: Distribution of population by age compare to sex $(\mathrm{N}=105)$

\begin{tabular}{|c|c|c|c|c|c|}
\hline Age group in year & Female & Prevalence (\%) & Male & Prevalence (\%) & Total prevalence (\%) \\
\hline $0-6$ & 10 & 9.5 & 7 & 6.66 & 16.20 \\
\hline $7-12$ & 14 & 13.33 & 8 & 7.61 & 20.95 \\
\hline $13-18$ & 6 & 5.71 & 5 & 4.7 & 10.43 \\
\hline $19-24$ & 7 & 6.66 & 8 & 7.61 & 14.28 \\
\hline $25-30$ & 8 & 7.61 & 1 & 0.95 & 5.8 \\
\hline $31-36$ & 4 & 3.8 & 1 & 0.95 & 4.7 \\
\hline $43-48$ & 2 & 1.9 & 2 & 1.9 & 3.8 \\
\hline $49-54$ & 1 & 0.95 & 3 & 2.85 & 3.8 \\
\hline $55+$ & 6 & 5.71 & 4 & 3.8 & 9.5 \\
\hline Total & 61 & 58.09 & 44 & 41.91 & 100 \\
\hline
\end{tabular}


The highest prevalence $13.33 \%$ in female were in the 7-12 years and lowest prevalence $0.95 \%$ in $49-54$ years. The highest prevalence $7.62 \%$ in male were in the 7-12 years and lowest prevalence $0.95 \%$ in $25-30$ years and 31-36 years [Table \& Figure-3].

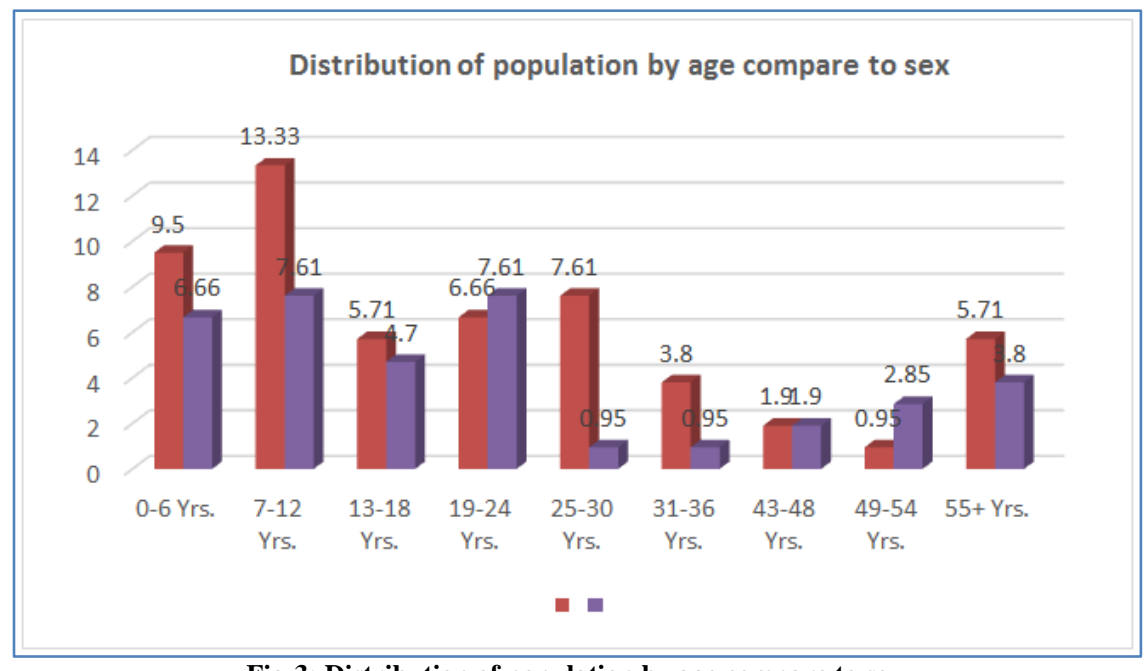

Fig-3: Distribution of population by age compare to sex.

Table-4: Distribution of sites of Rash in patients $(\mathrm{N}=105)$

\begin{tabular}{|c|c|c|}
\hline $\begin{array}{c}\text { Site of } \\
\text { infection }\end{array}$ & $\begin{array}{c}\text { Number of } \\
\text { patient }\end{array}$ & $\begin{array}{c}\text { Prevalence } \\
(\boldsymbol{\%})\end{array}$ \\
\hline Finger & 17 & 16.20 \\
\hline Shoulder blades & 6 & 5.71 \\
\hline Armpits & 8 & 7.61 \\
\hline Chest & 6 & 5.71 \\
\hline Wrist (belt line) & 30 & 28.57 \\
\hline Inner thighs & 8 & 7.61 \\
\hline Heel & 12 & 11.42 \\
\hline Nail & 18 & 17.14 \\
\hline Total & 105 & 100 \\
\hline
\end{tabular}

It appears that most of the patients are affected at multiple sites. Within the considering sites wrist (belt line) and nail show severity. Observation implies that the most common site for mites to be found is between the folds in the skin, especially where the skin is thin. In infants face and scalp are also involved but it does not mention here [Table-4].

Table-5: Seasonal variation of scabies infection $(\mathrm{N}=105)$

\begin{tabular}{|l|c|c|}
\hline \multicolumn{1}{|c|}{ Month name } & Number of patient & Prevalence (\%) \\
\hline April-May & 10 & 9.5 \\
\hline June-July & 13 & 12.38 \\
\hline $\begin{array}{l}\text { August- } \\
\text { September }\end{array}$ & 17 & 16.20 \\
\hline $\begin{array}{l}\text { October- } \\
\text { November }\end{array}$ & 30 & 28.57 \\
\hline $\begin{array}{l}\text { December- } \\
\text { January }\end{array}$ & 35 & 33.33 \\
\hline \multicolumn{1}{|c|}{ Total } & 105 & 100 \\
\hline
\end{tabular}

November (28.57\%), December and January $(33.33 \%)$ show the highest prevalence in scabies infection. In Bangladesh, this three months represent a winter season. On the other hand, July to October represent almost hot condition. So from my result, it is concluded that scabies infection is more prevalent in winter than summer [Table-5]. 


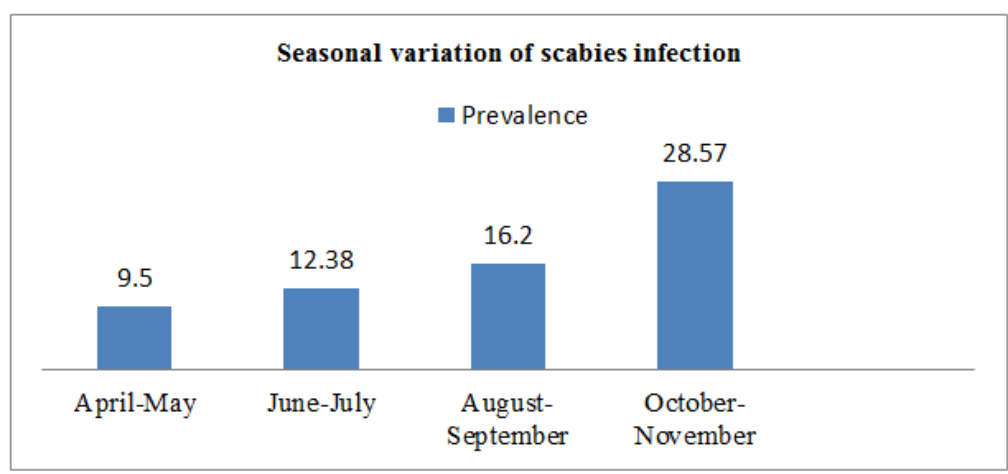

Fig-4: Seasonal variation of scabies infection

Table-6: Prevalence of scabies infection with Re-infection ( $N=105)$

\begin{tabular}{|c|c|c|}
\hline $\begin{array}{c}\text { Re-infection } \\
\text { history }\end{array}$ & $\begin{array}{c}\text { Number of } \\
\text { patient }\end{array}$ & Prevalence (\%) \\
\hline Present & 20 & 19.04 \\
\hline Absent & 85 & 80.96 \\
\hline Total & 105 & 100 \\
\hline
\end{tabular}

Among the 105 patients, 20(19.04\%) respondents had re-infection history and $85(80.96 \%)$ respondents had not any re-infection history. So most of the patients had no re-infection. I would like to mention that patients of scabies follow doctor advice perfectly when they treated. Such as they must avoid body contact until they and their partners and close contact have been treated. Partner and close contact should be treated simultaneously. These are the essential precautions in scabies re-infection [Table-6].

Table-7: Prevalence of Re-infection times of scabies infection ( $N=105)$

\begin{tabular}{|l|c|c|}
\hline $\begin{array}{c}\text { Times of Re- } \\
\text { infection }\end{array}$ & $\begin{array}{c}\text { Number of } \\
\text { patient }\end{array}$ & Prevalence (\%) \\
\hline Second time & 17 & 85 \\
\hline Third time & 3 & 15 \\
\hline More than Third & 0 & 0 \\
\hline Total & 20 & 100 \\
\hline
\end{tabular}

Among 105 patients, 20 patients had reinfection history. Among them 17(85\%) had second time reinfection, $3(15 \%)$ patients had third time reinfection [Table-7].

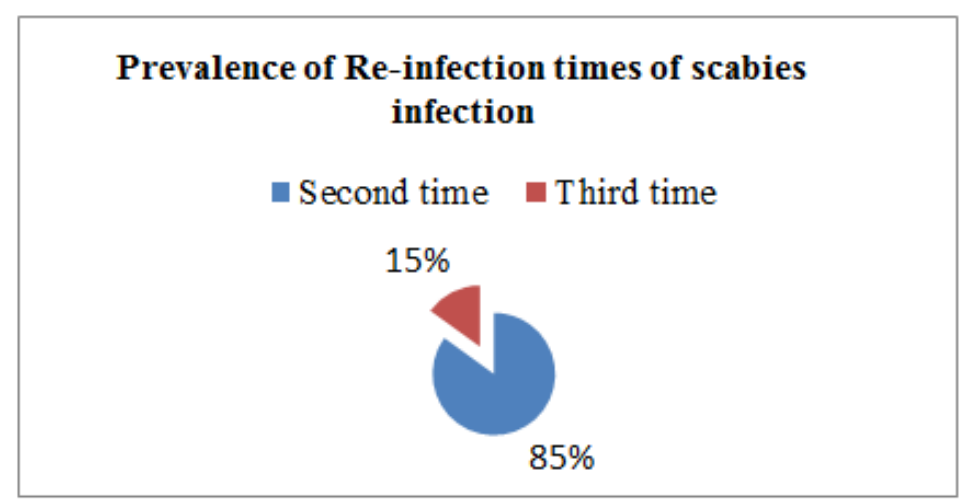

Fig-5: Prevalence of Re-infection times of scabies infection.

Table-8: Prevalence of family history of scabies Infection ( $N=105)$

\begin{tabular}{|c|c|c|}
\hline $\begin{array}{c}\text { History of scabies } \\
\text { infection }\end{array}$ & $\begin{array}{c}\text { Number of } \\
\text { patient }\end{array}$ & $\begin{array}{c}\text { Prevalence } \\
(\%)\end{array}$ \\
\hline Present & 8 & 7.6 \\
\hline Absent & 97 & 92.4 \\
\hline Total & 105 & 100 \\
\hline
\end{tabular}


The total studied patients were 105. Among them $8(7.6 \%)$ respondents had the scabies infection history in their family and others had no history. So scabies infection does not depend on genetic basis [Table-8].

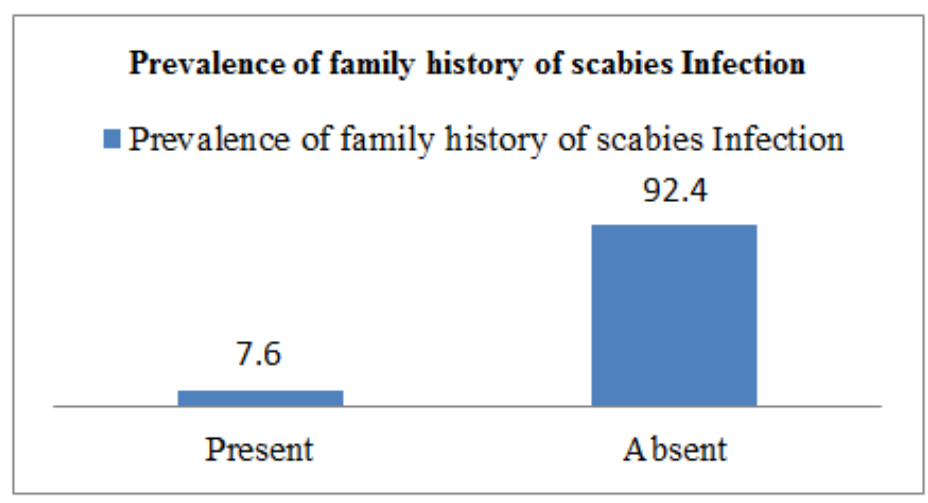

Fig-6: Prevalence of family history of scabies Infection

Table-9: Treatment history of scabies infection and its prevalence rate $(\mathrm{N}=105)$

\begin{tabular}{|l|c|c|}
\hline Times of treatment & Number of patient & Prevalence (\%) \\
\hline First time & 95 & 90.47 \\
\hline Second time & 9 & 8.5 \\
\hline More than twice & 1 & 0.95 \\
\hline Total & 105 & 100 \\
\hline
\end{tabular}

It was observed from the table result that Scabies infection is easily curable but need carefulness about doctor advices and most of the patients follow doctor guidelines perfectly [Table-9].

Table-10: Distribution of respondents by their educational status $(\mathrm{N}=105)$

\begin{tabular}{|l|c|c|}
\hline Educational status & $\begin{array}{c}\text { Number of } \\
\text { respondents }\end{array}$ & Prevalence (\%) \\
\hline Primary level & 43 & 40.95 \\
\hline Secondary level & 5 & 4.7 \\
\hline Higher secondary level & 10 & 9.5 \\
\hline Horns & 20 & 19.04 \\
\hline Illiterate group & 27 & 25.71 \\
\hline Total & 105 & 100 \\
\hline
\end{tabular}

It was draw from the table that Scabies infection is not completely dependable on educational status but need consciousness that stop hygienic practice and avoid over crowded place. Health education should be included in educational curriculum and patients especially mothers and teachers should be educated in the light of health education, that the peoples can be introduced to the self-care system for themselves from the childhood. Health education through the mass media should be provided in simple, easily understandable way regarding the cause and preventive measures of scabies infection. School health should be introduced for practical application of hygienic practice [Table \& Figure-10-7].

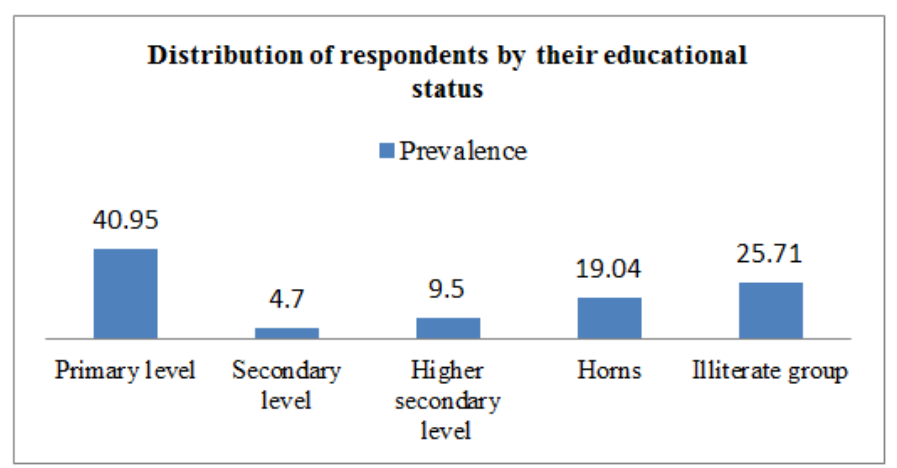

Fig-7: Distribution of respondents by their educational status. 
Table-11: Distribution of respondents by their Occupation $(\mathrm{N}=105)$

\begin{tabular}{|l|c|c|}
\hline $\begin{array}{c}\text { Occupation } \\
\text { categories }\end{array}$ & $\begin{array}{c}\text { Number of } \\
\text { respondents }\end{array}$ & $\begin{array}{c}\text { Prevalence } \\
(\mathbf{\%})\end{array}$ \\
\hline Student & 30 & 28.57 \\
\hline Nurse & 10 & 9.5 \\
\hline Hospital patient & 6 & 5.71 \\
\hline Housewife & 9 & 8.5 \\
\hline Hostel member & 15 & 14.28 \\
\hline Garments worker & 22 & 20.58 \\
\hline Others & 13 & 12.38 \\
\hline \multicolumn{1}{|c|}{ Total } & 105 & 100 \\
\hline
\end{tabular}

Student and garments worker were mostly affected with scabies infection because they were busy with crowded place [Table $11 \&$ Figure 8].

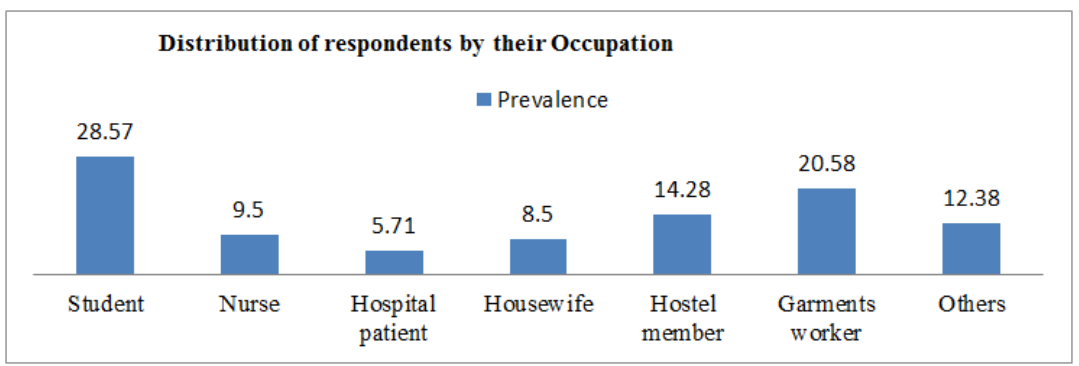

Fig-8: Distribution of respondents by their Occupation.

Table-12: Prevalence of respondents with crowed place, Bed and cloth sharing habit $(\mathrm{N}=105)$

\begin{tabular}{|l|c|c|}
\hline Category & Respondents & $\begin{array}{c}\text { Prevalence } \\
(\%)\end{array}$ \\
\hline Present & 72 & 68.57 \\
\hline Absent & 33 & 31.43 \\
\hline Total & 105 & 100 \\
\hline
\end{tabular}

Almost two-third $(68.57 \%)$ of the patient who affect with scabies live in crowded place and show bed and cloth sharing habit [Table-12 \& Figure-9].

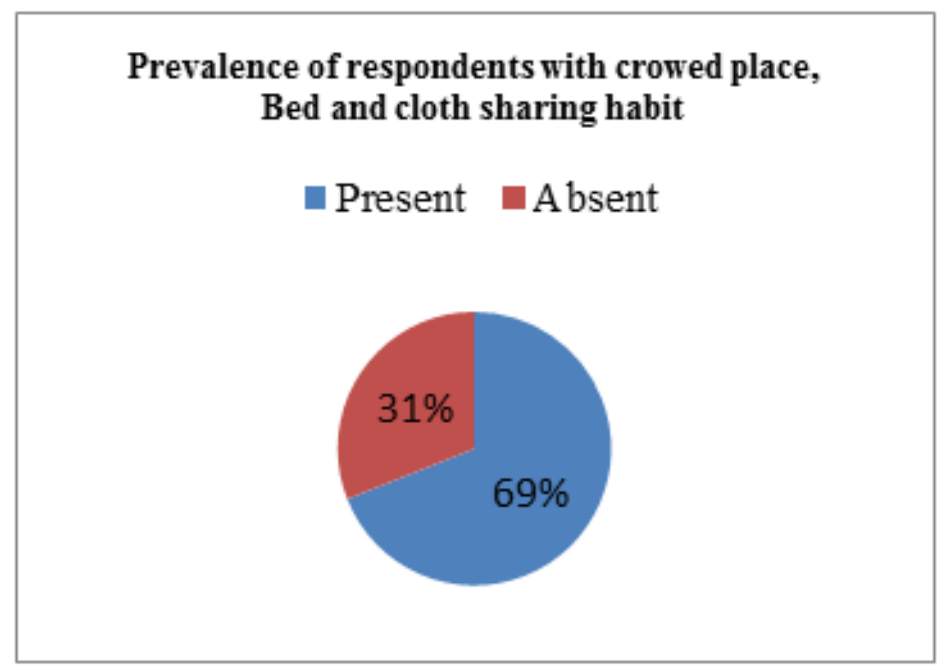

Fig-9: Prevalence of respondents with crowed place, Bed and cloth sharing habit 
M. Moniruzzaman Khan et al; Saudi J Med Pharm Sci, May, 2020; 6(5): 405-415

Table-13: Counting rash number is used to determine the severity of Scabies infection by CGS (clinical grading score) $(\mathrm{N}=\mathbf{1 0 5})$

\begin{tabular}{|c|c|c|c|c|}
\hline $\begin{array}{c}\text { Rash } \\
\text { number }\end{array}$ & Severity & CGS & $\begin{array}{c}\text { No. of } \\
\text { patient }\end{array}$ & $\begin{array}{c}\text { Prevalence } \\
(\%)\end{array}$ \\
\hline $1-10$ & Mild & 1 & 38 & 36.19 \\
\hline $11-20$ & Moderate & 2 & 52 & 49.52 \\
\hline $21-30$ & Severe & 3 & 14 & 13.33 \\
\hline $31+$ & Crusted & 4 & 1 & 0.95 \\
\hline Total & & & 105 & 100 \\
\hline
\end{tabular}

Scabies infection is not serious problem for our country because the highest prevalence (49.52$50 \%$ ) of severity of scabies infection limited with in Moderate (second stage of classical scabies infection) category. Classical scabies is more active in Bangladesh; on the other hand crusted scabies is not available in Bangladesh [Table-13].

Table-14: Identifying possible contact tracing of infected patient $(\mathrm{N}=105)$

\begin{tabular}{|l|c|c|}
\hline Category & Number of patient & Prevalence (\%) \\
\hline Carrier & 76 & 72.38 \\
\hline Non carrier & 29 & 27.62 \\
\hline Total & 105 & 100 \\
\hline
\end{tabular}

From this it was observed that most of the cases scabies is transmitted from infected person to non-infection person due to wanting of their consciousness [Table-14 \&Figure-10].

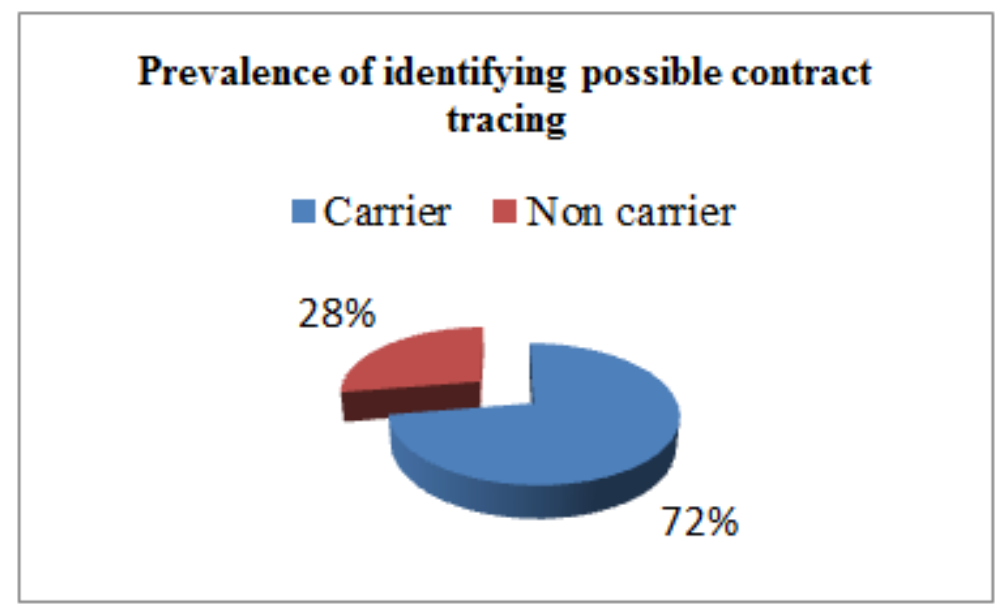

Fig-10: Identifying possible contact tracing of infected patient

The application of antibiotic is not available in the treatment of scabies infection. Permethrin, Benzyl benzoate and invermectin are the most efficacy medicine. The treatment of scabies infection is not expensive. The application of Medicine is not all if the patient neglects doctor advice.

\section{DISCUSSION}

Based on the results of the study, most of the respondent's shares one bedroom while the rest did not shares bedrooms. The majority of the patients shared towels during bathing while the rest did not share towels. This may serve as a risk factor for the transmission of scabies among family members. These results are similar to a study done [12]. It reported similar characteristics of a typical family with scabies including increased number of household members, presence of other family members with scabies, overcrowding, poverty and low educational attainment. These characteristics may contribute greatly to the transmission of the mites. In terms of age group, the majority are the children who are usually affected by the disease. The result of this study is coincide with the study done [12]. Children are usually affected because they hardly maintained their hygienic practices. The majority of the children are those who are nonschooling ages from 6months to 6year and in those children in both elementary level. The sites of the scabies lesions before treatment. The majority of respondents have lesions on the abdominal area, which has the highest prevalence of scabies lesion. The other top sites are as follows: finger and nail. These results more or less complemented another study made by Salazar, et al.[17], who reported the 6 preferred sites of scabies (in decreasing frequency): interdigital webs, 
wrists, arms, axilla, lower abdomen, buttocks and from the study of wherein she reported top site is at the abdominal area, the other top sites (in decreasing frequency) were pubic area $(68.2 \%)$, buttocks and left hand $(63.4 \%)$, right hand $(60.9 \%)$, and left leg $(46.3 \%)$ [12]. Although not in the same order, both studies imply that the most common site for mites to be found is between the folds in the skin, especially where the skin is thin. According to Fernandez M.D. (2006), this may be related to the site of mite transfer, the thickness of the skin layer or the slightly higher temperatures in the skin, since the mites survive less in dry and cold temperature [12]. It was draw from the table that Scabies infection is not completely dependable on educational status but need consciousness that stop hygienic practice and avoid over crowded place. Health education should be included in educational curriculum and patients specially mothers and teachers should be educated in the light of health education, that the peoples can be introduced to the self-care system for themselves from the childhood. Health education through the mass media should be provided in simple, easily understandable way regarding the cause and preventive measures of scabies infection. School health should be introduced for practical application of hygienic practice. In this study the re-infection of scabies. Among the 105 patients, 20(19.04\%) respondents had re-infection history and 85(80.96\%) respondents had not any re-infection history. So most of the patients had no re-infection. I would like to mention that patients of scabies follow doctor advice perfectly when they treated. Such as they must avoid body contact until they and their partners and close contact have been treated. Partner and close contact should be treated simultaneously. These are the essential precautions in scabies reinfection. Clinicians and drug companies recommended treatment of family members and close contacts at the same time as cases, to improve cure rates and reduce reinfection. Seasonal variation in scabies infection. From the result of table, November, December and January show the highest prevalence in scabies infection. In Bangladesh, these three month represent a winter season. On the other hand, July to October represent almost hot condition. So from my result, it is concluded that scabies infection is more prevalent in winter than summer which is matching with the study done by [2]. Serious adverse effects have been associated with the use of some antiscabietic treatments. Convulsions and aplastic anaemia have been reported with the use of lindane [14], and an increased risk of death amongst elderly patients has been reported with the use of invermectin [13]. Evidence of cure ideally requires follow up for about one month. This allows time for lesions to heal and for any eggs and mites to reach maturity if treatment fails (ie beyond the longest incubation interval). Patients should be warned that itching may persist for one to two weeks after treatment, even if the mite is successfully eradicated [15]. Because of this delay in symptom relief it may sometimes be difficult to distinguish reinfestation from primary treatment failure. Contacts of cases are usually advised to treat themselves at the same time as the case in order to reduce the risk of reinfestation [16]. Prevention is rased on principles common to most infectious diseases, that is, limitation of contact with the mite. Using data from randomized controlled trials, this review examines the existing evidence of effectiveness of treatments for scabies. The incidence of scabies infection in the Bangladesh is not known. However, data on annual incidence of scabies seen in one health institution in Dhaka showed a rate of 45 per 1000 patients. Toxins secreted by the mites are responsible for the development of vesiculopapular lesions with pruritus. Initial predilection sites occur around finger webs, wrists or elbows, and anterior axillary folds. In untreated individuals, other parts of the body are involved. Based on study, the first evidence of parasitization consists of a small erythematous eruption or "watery blister" [17]. Susceptibility to scabies is universal. Since the principal mode of transmission is direct transfer of ectoparasites through personal contact, the disease is particularly rampant in overcrowded places without adequate sanitation. Children younger than 15 years have the highest prevalence of scabies. Other at-risk populations include persons who are sexually active, debilitated, or immunocompromised. Currently, there are numerous medical treatments available for scabies. Most of these are effective. Permethrin cream 5\% (Elimite) is the current drug of choice, especially for infants more than 2 months and small children. Other standard treatment for scabies is topical application of $1 \%$ gamma benzenehexachloride, crotamiton, $5 \%$ tetraethylthiuram monosulfide, benzyl benzoate, and sulfur. Some of these are potentially toxic chemicals. There are some concerns about systemic toxicity. In fact, there are several herbal products that are as effective measures for some common diseases such as Scabies infection. The pathognomic signs of scabies are burrows, erythematous papules, and generalized pruritus with nocturnal dominance. An atypical form, known as crusted scabies, present $\mathrm{s}$ as a psoriaform dermatitis with variable whitish scaling and mild or no pruritus [6]. In class ic scabies the estimated number of mites per patient is 10 to 15 , as compared with over 1 million 762 MATHEI"etalin crusted scabies. The numerous mites found in crusted scabies facilitate transmission through the environment. The crusts flake off, contaminate the environment, and mites survive in the environment for up to 3 days. By contras $\mathrm{t}$, in classic scabies the environment plays a minor role in transmission. Crusted scabies are frequently found in immunocompromized patients, such as patients infected with HIV, patients receiving immunosuppressive therapy, individuals with men talretardation, and a d institutionalized Elderly people. Within nursing homes, residents with unrecognized crusted Scabies often constitute a source for spread of scabies to other residents and staff members. Scabies out breaks have 
been frequently documented in nursing homes. In a survey of 130 nursing homes in Canada, 25\% reported cases of scabies among their residents during a 1-year period, over a 1 -year period, $17 \%$ of Michigan's nursing homes reported scabies in the facility.

\section{CONCLUSION}

At the end of this study, the researcher was able to arrive at the following Conclusion Scabies is more common where overcrowded conditions prevail; it can affect any individual irrespective of social status, personal hygiene, profession, gender, age or ethic origin. The typical family of the respondents with scabies has certain characteristics that may contribute greatly to the spread of mites. These include increased number of household members, presence of other family members with scabies, overcrowding, poverty and low educational attainment. Children (1-12yo) have the highest incidence of scabies as compared to the other age group. There is a slight preponderance of scabies among males. Scabies are more prominent in skin folds. The top five sites of predilection of scabies lesions in decreasing order is abdominal area, right hand, right thigh, left hand, and buttocks. People should maintain an advice to avoid body contact until they and their partners and close contact have been treated. Partner and close contact should be treated simultaneously. Topical permethrin appears to be the most effective treatment for scabies. Ivermectin appears to be an effective oral treatment. Classical scabies is more active in Bangladesh as a moderate form.

\section{REFERENCES}

1. Alexander, J. 0. (1984). Arthropods and human skin. Springer-Verlag, Berlin, Germany.

2. Downs, A. M. R., Harvey, I., \& Kennedy, C. T. C. (1999). The epidemiology of head lice and scabies in the UK. Epidemiology \& infection, 122(3), 471477.

3. Bezold, G., Lange, M., Schiener, R., Palmedo, G., Sander, C. A., Kerscher, M., \& Peter, R. U. (2001). Hidden scabies: diagnosis by polymerase chain reaction. British Journal of Dermatology, 144(3), 614-618.

4. Heukelbach, J., Van Haeff, E., Rump, B., Wilcke, T., Moura, R. C. S., \& Feldmeier, H. (2003). Parasitic skin diseases: health care- seeking in a slum in north- east Brazil. Tropical Medicine \& International Health, 8(4), 368-373.
5. Chosidow, O. (2006). Scabies, ft. Engl. J. Med. 354:1718-1727.

6. Sehgal, V. N., Malhotra, S., \& Ramesh, V. (2015). Nodular Scabies of the Genitals. Int J Dermatol Clin Res 1 (1): 010.

7. Green, M. S. (1989). Epidemiology of scabies. Epidemiol. Rev. 11:126-150.

8. Heukelbach, J., Wilcke, T., Winter, B., de Oliveira, F. A. S., Moura, R. C. S., Harms, G., ... \& Feldmeier, H. (2004). Efficacy of ivermectin in a patient population concomitantly infected with intestinal helminths and ectoparasites. Arzneimittelforschung, 54(07), 416421.

9. Fain, A. (1978). Epidemiological problems of scabies. Int. J. Dermatol. 17:20-30.

10. Fain, A. (1968). Etude de la variabilit e de Sarcoptes scabiei avec une revision des Sarcoptidae. Acta Zool. Pathol Antverp. 47:1-196.

11. Arlian, L. G., Morgan, M. S., Estes, S. A., Walton, S. F., Kemp, D. J., \& Currie, B. J. (2004). Circulating IgE in patients with ordinary and crusted scabies. Journal of medical entomology, 41(1), 74-77.

12. Walton, S. F., \& Currie, B. J. (2007). Problems in diagnosing scabies, a global disease in human and animal populations. Clinical microbiology reviews, 20(2), 268-279.

13. Hollanders, W., Vercruysse, J., Raes, S., \& Bornstein, S. (1997). Evaluation of an enzymelinked immunosorbent assay (ELISA) for the serological diagnosis of sarcoptic mange in swine. Veterinary parasitology, 69(1-2), 117-123.

14. Gibbs, S. A. M. (1996). Skin disease and socioeconomic conditions in rural Africa: Tanzania. International journal of dermatology, 35(9), 633-639.

15. Arlian, L. G., Morgan, M. S., \& Neal, J. S. (2003). Modulation of cytokine expression in human keratinocytes and fibroblasts by extracts of scabies mites. The American journal of tropical medicine and hygiene, 69(6), 652-656.

16. Heukelbach, J., Van Haeff, E., Rump, B., Wilcke, T., Moura, R. C. S., \& Feldmeier, H. (2003). Parasitic skin diseases: health care- seeking in a slum in north- east Brazil. Tropical Medicine \& International Health, 8(4), 368-373.

17. Brook, I. (1995). Microbiology of secondary bacterial infection in scabies lesions. Journal of clinical microbiology, 33(8), 2139-2140. 